\title{
Case-control study of the health of those looked after by local authorities
}

\author{
J Williams, S Jackson, A Maddocks, W-Y Cheung, A Love, H Hutchings
}

\begin{abstract}
Aims-To assess the health needs and provision of health care to school age children in local authority care.

Methods-A total of 142 children aged 5 to 16 in local authority care, and 119 controls matched by age and sex were studied. Main outcome measures were routine health care, physical, emotional, and behavioural health, health threatening and antisocial behaviour, and health promotion.

Results-Compared with children at home, those looked after by local authorities were significantly more likely to: experience changes in general practitioner; have incomplete immunisations; receive inadequate dental care; suffer from anxieties and difficulties in interpersonal relationships; wet the bed; smoke; use illegal drugs; and have been cautioned by police or charged with a criminal offence. They also tend to receive less health education. They were significantly more likely to have had a recent hearing or eye sight test, and reported significantly less physical ill health overall.

Conclusions-The overall health care of children who have been established in care for more than six months is significantly worse than for those living in their own homes, particularly with regard to emotional and behavioural health, and health promotion. In contrast to uncontrolled observational studies we have not found evidence of problems with the physical health of these children. (Arch Dis Child 2001;85:280-285)
\end{abstract}

Keywords: looked-after children; physical health; emotional and behavioural health; health promotion

No comparative controlled study of the health and health needs of children in the care system has yet been reported, but there have been uncontrolled observational studies from Britain and the United States with findings that give cause for concern. Children entering the care system often come from severely disadvantaged families and are at high risk of poor mental and physical health. ${ }^{1-3}$ There is well documented research evidence that the physical health of children entering care is compromised, but objective comparative research on the long term health status of children in care is conspicuous by its absence, especially for older children, both in the United States and in Britain. Many untreated chronic medical conditions have been noted in American studies, but these studies are based on an assessment of children who are entering the care system. ${ }^{4-6}$ In Britain, Bamford and Wolkind in $1988^{7}$ drew attention to the poor physical and mental health of children in care but noted that those who were still in care at 16 years of age were in good physical health, although more likely to be clumsy or have speech problems than their peers who had not been in care. Mather and colleagues $^{8}$ noted poor physical health findings in 194 children in care in Greenwich, representing $25 \%$ of the looked after children in the area. Poor attendance at statutory medicals was noted in the small sample reported by Butler and Payne $^{910}$ who reported poor physical health after studying the notes of 51 children (26 of whom were examined).

Previous studies have consistently stressed the emotional and behavioural difficulties these children experience, particularly if they have been previously abused. ${ }^{11-13}$ It is also acknowledged that delivery of effective health services to looked after children has not been well coordinated and, until recently, not well planned. ${ }^{14}$

Findings from uncontrolled observational studies of children entering the care system may not portray an accurate picture of the health and health needs of children who are established in care. Our purpose was to identify the health and needs of children who have been established in local authority care for at least six months, and to determine how well these are being met, by controlled comparison with children living in their own homes. Health needs in this context include mental, emotional, and physical health, health education, and promotion.

\section{Methods}

PROTOCOL

The study was conducted in close collaboration with the Welsh unitary authorities of Swansea, Neath Port Talbot, Bridgend and, later in the study, Pembrokeshire. Children who had been looked after by a local authority for more than six months were included, provided they were over 4 and under 17 on 1 November 1997. (The 1989 Children Act introduced the term "looked after" to replace "in care", which technically refers only to children subject to a court order.) Local authority care included placements with foster families, relatives or friends, or in community homes. We excluded those who were placed with their own families, and those who were in secure units or had severe learning difficulties, as the numbers were small, but the problems likely to be severe. Children were identified through social service departments, and cooperation was obtained from the responsible social worker, who helped arrange the interview with 
Subjects

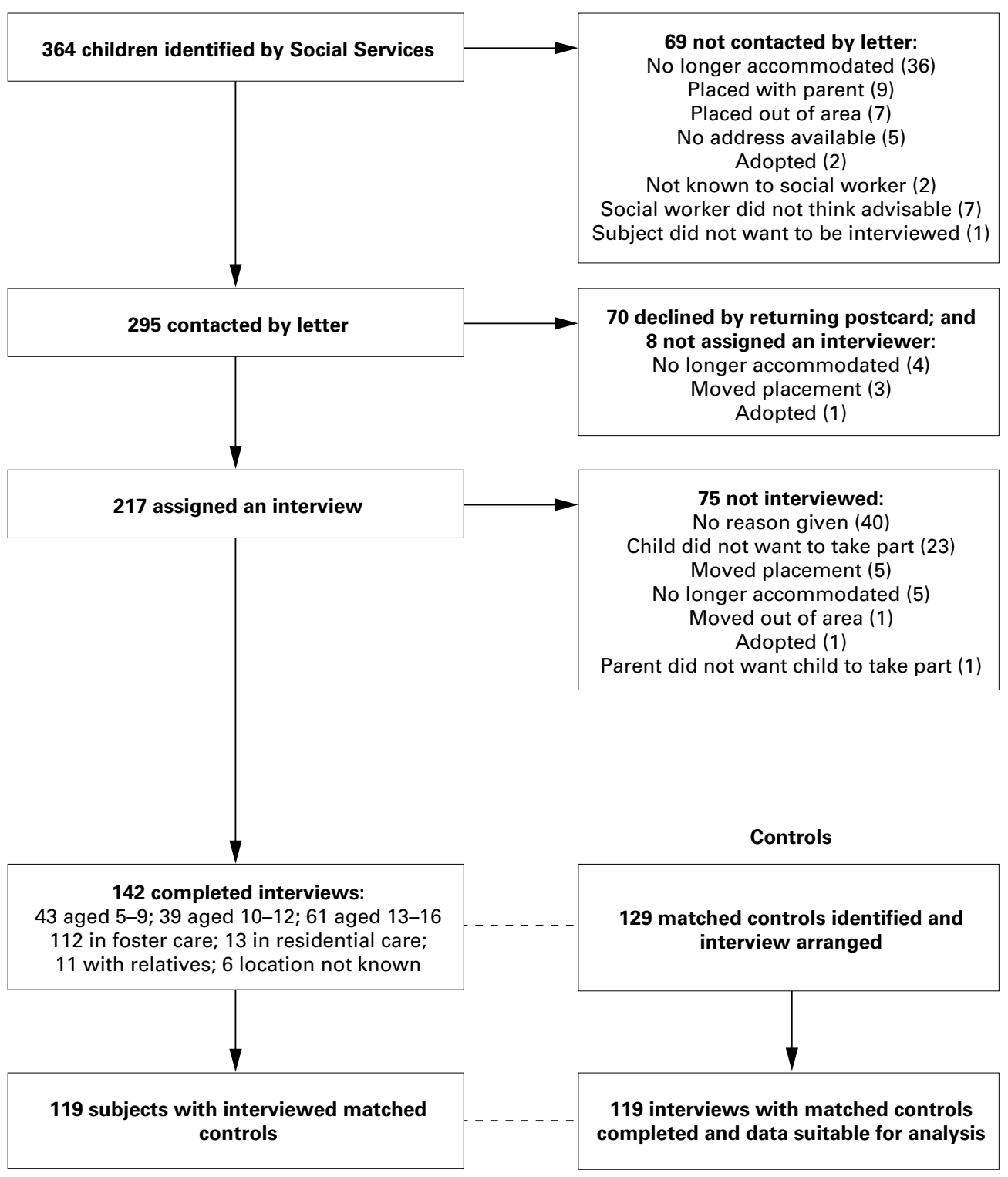

Figure 1 Participation of subjects and controls in the study.

the child and carer. The initial approach was by letter, which gave an opportunity to opt out before contact was made and formal consent obtained.

Controls were identified from the Welsh Child Health Computer, matched for gender and date of birth, and living in the Swansea, Neath Port Talbot, and Bridgend unitary authority areas. The parents or guardian of the child were approached by letter asking permission for the child to participate in the study. If a stamped addressed postcard was returned refusing interview, we substituted a child of the same sex with the next closest birthday.

All interviews took place in the children's homes or on neutral territory to avoid any risk of stigmatisation. They were undertaken by trained contract researchers, and took 30-45 minutes, depending on the age of the child and the complexity of any issues raised. Whenever possible children over 11 were interviewed on their own. Two sections of the Looking After
Children Assessment and Action Records ${ }^{15}$ were used as the basis for the interview schedule, with some modifications. Additional demographic questions were included and some questions designed for children in local authority accommodation were omitted as inappropriate for those living with their families. Cartoons and pictures were used to make the instrument as child friendly as possible. The instrument was piloted in Carmarthen, and the content found to be acceptable, except for the sections on behavioural and emotional status, which required simplification. The adapted version was tested for reliability and construct validity before use (paper in preparation).

Although discussion is encouraged when the questionnaire is used in social work, it was completed without discussion of the answers for the purposes of this research. At the end of the interview, parents or carers were invited to comment more generally on their experience of looking after the child's health and on any 
Table 1 Measures relating to routine health care

\begin{tabular}{|c|c|c|c|c|c|}
\hline Measure & $\begin{array}{l}\text { Matched } \\
\text { pairs }\end{array}$ & Subjects & Controls & $p$ value & $\begin{array}{l}95 \% \text { CI of the } \\
\text { difference }\end{array}$ \\
\hline $\begin{array}{l}\text { Number always registered with the } \\
\text { same GP }\end{array}$ & 117 & 40 & 96 & $<0.001$ & $-59 \%$ to $-37 \%$ \\
\hline Mean time since a hearing test (mth) & 83 & 13.14 & 61.85 & $<0.001$ & -58.82 to -38.59 \\
\hline $\begin{array}{l}\text { Mean time since an eyesight test } \\
\text { (mth) }\end{array}$ & 119 & 7.93 & 13.57 & 0.006 & -9.62 to -1.66 \\
\hline $\begin{array}{l}\text { Number having regular dental check } \\
\text { ups }\end{array}$ & 112 & 85 & 101 & 0.004 & $-23 \%$ to $-5 \%$ \\
\hline $\begin{array}{l}\text { Number needing dental treatment at } \\
\text { last visit }\end{array}$ & 110 & 57 & 42 & 0.044 & $1 \%$ to $27 \%$ \\
\hline Number fully immunised for age & 86 & 35 & 48 & 0.015 & $-26 \%$ to $-4 \%$ \\
\hline $\begin{array}{l}\text { Number over } 12 \text { fully immunised for } \\
\text { age }\end{array}$ & 58 & 12 & 22 & 0.041 & $-32 \%$ to $-3 \%$ \\
\hline
\end{tabular}

Table 2 Physical health reported

\begin{tabular}{llllll}
\hline Conditions reported & $\begin{array}{l}\text { Matched } \\
\text { pairs }\end{array}$ & $\begin{array}{l}\text { Number of } \\
\text { subjects }\end{array}$ & $\begin{array}{l}\text { Number of } \\
\text { controls }\end{array}$ & p value & $\begin{array}{l}95 \% \text { CI of the } \\
\text { difference }\end{array}$ \\
\hline Any medical conditions & 112 & 72 & 84 & 0.111 & $-23 \%$ to $1 \%$ \\
Non-infectious skin conditions & 112 & 12 & 27 & 0.014 & $-23 \%$ to $-4 \%$ \\
Infectious skin conditions† & 112 & 17 & 36 & 0.005 & $-28 \%$ to $-6 \%$ \\
Respiratory tract conditions $\ddagger$ & 112 & 21 & 32 & 0.108 & $-21 \%$ to $1 \%$ \\
Gastrointestinal ailments & 112 & 6 & 10 & 0.388 & $-0.1 \%$ to $2 \%$ \\
Bed wetting & 112 & 10 & 2 & 0.039 & $1.2 \%$ to $13 \%$ \\
\hline
\end{tabular}

${ }^{\star}$ Eczema, acne, psoriasis, dermatitis.

+Wart, impetigo, athlethe's foot, verruca, scabies.

$\ddagger$ Tonsillitis, glue ear, hearing problems, asthma, chesty cough.

§Stomach pain, sickness, diarrhoea, stomach spasm.

Table 3 Emotional and behavioural health (mean scores from emotional and behavioural scales)

\begin{tabular}{llllll}
\hline Measure (age group) & $\begin{array}{l}\text { Matched } \\
\text { pairs }\end{array}$ & Subjects & Controls & p value & $\begin{array}{l}\text { 95\% CI of the } \\
\text { difference }\end{array}$ \\
\hline Interpersonal relationships (5-9 y) & 33 & 74.24 & 84.29 & 0.007 & -17.08 to -3.01 \\
Impetuous behaviour score (5-9 y) & 33 & 50.30 & 33.43 & 0.005 & 5.62 to 28.11 \\
Unsettledness score (5-9 y) & 34 & 23.01 & 15.69 & 0.088 & -1.14 to 15.78 \\
Interpersonal relationships (10-16 y) & 78 & 62.50 & 69.12 & 0.001 & -10.48 to -2.76 \\
Anxieties and worries (10-16 y) & 81 & 22.05 & 15.38 & 0.007 & 1.89 to 11.45 \\
Behavioural problems (10-16 y) & 81 & 37.54 & 24.25 & $<0.001$ & 7.34 to 19.26
\end{tabular}

A higher score indicates better interpersonal relationships, but increased behaviour problems, unsettledness, anxieties, and worries.

problems they had encountered. These comments were taped and transcribed for analysis, with permission.

DATA ANALYSIS

Completed questionnaires were optically scanned into SPSS. ${ }^{16}$ Quantitative data were analysed using the paired $t$ test and McNemar's test ${ }^{17}$ based on matched pairs. Where a question was not answered, the matched pair was excluded from the analysis. Qualitative data on physical health and unmet needs were assessed by two paediatricians working independently. Any differences were resolved by discussion, before analysis using McNemar's test, based on presence or absence of conditions. The views of children and carers/parents were compared using Bland and Altman's method. ${ }^{18}$

ETHICS

The study was approved by the West Glamorgan Local Research Ethics Committee and all subjects or parents/guardians gave written consent following oral and written explanation.

\section{Results}

PARTICIPATION

Out of 364 names supplied by Social Services departments, 142 looked after children were interviewed. Figure 1 shows the reasons for loss of subjects. For 135 subjects the child or parent declined the interview. Analysis of a random sample of $16 \%$ of the notes of "refusers" did not reveal any significant differences from a matched group of participants when the following were compared: numbers of addresses, statement of special educational needs, number of schools attended, changes of general practitioner, attendance for "in-care" medical, immunisation status, whether receiving specialist health care, and whether they were currently seeing a mental health professional.

Interviews were completed for 119 controls. The range of Townsend scores ${ }^{19}$ for the electoral ward of residence (median -0.85), indicated that these chidren were representative of the three local authority areas in which they lived, and not significantly different from electoral wards without control children (median $-0.24 ; p=0.38$ ). As a group, there was no significant difference between the 119 looked after children who were matched and the 23 for whom controls were not interviewed, for any of the parameters measured.

\section{FINDINGS}

Almost all children in both groups were registered with a general practitioner (GP), but looked after children were significantly more likely to have changed their GP at least once (table 1). Looked after children were significantly less likely to be fully immunised for their age, although the difference was not apparent for younger children. Eighty seven (74\%) claimed that they had attended an annual medical examination, and hearing or eyesight tests were significantly more recent than for control children (table 1). However, fewer looked after children visited a dentist regularly, and they were significantly more likely to need treatment when they did. Looked after children reported less physical ill health overall, particularly for skin conditions, but bed wetting was more common (table 2). They tended to have significantly more difficulties with interpersonal relationships, more anxieties and worries, and behavioural problems (table 3), and more looked after children were aware of needing help for emotional and behavioural problems (36/119 v 3/119, $\mathrm{p}<0.001 ; 95 \%$ confidence interval (CI) of the difference $20 \%$ to $38 \%$ ). Sixty four looked after children had or were expecting contact with a mental health professional (34 were waiting for an appointment at the time of interview), compared with five (three waiting for appointments) control children. Looked after children over 9 years of age were more likely to smoke, use illegal drugs, have been cautioned or charged with a criminal offence, and admit to having done something that could get them into serious trouble (table 4). There was a trend for looked after children to have received less advice on exercise, diet, smoking, alcohol, drugs, sexuality, and sex, but this only reached statistical significance for 
Table 4 Health threatening and antisocial behaviour (children aged 10-16 years)

\begin{tabular}{|c|c|c|c|c|c|}
\hline Question (Answer) & $\begin{array}{l}\text { Matched } \\
\text { pairs }\end{array}$ & $\begin{array}{l}\text { Number } \\
\text { of subjects }\end{array}$ & $\begin{array}{l}\text { Number } \\
\text { of controls }\end{array}$ & $p$ value & $\begin{array}{l}95 \% \text { CI of the } \\
\text { difference }\end{array}$ \\
\hline Do you smoke (Yes) & 75 & 25 & 7 & $<0.001$ & $13 \%$ to $35 \%$ \\
\hline Do you drink alcohol (Never) & 77 & 19 & 23 & 0.481 & $-5 \%$ to $16 \%$ \\
\hline Do you ever use any drugs (Yes) & 63 & 20 & 3 & $<0.001$ & $14 \%$ to $39 \%$ \\
\hline $\begin{array}{l}\text { Have you been cautioned or charged in } \\
\text { the past six months (Yes) }\end{array}$ & 77 & 16 & 5 & 0.027 & $3 \%$ to $25 \%$ \\
\hline $\begin{array}{l}\text { Have you done anything that might } \\
\text { have got you into serious trouble in } \\
\text { the past six months (Yes) }\end{array}$ & 65 & 13 & 2 & 0.007 & $6 \%$ to $28 \%$ \\
\hline
\end{tabular}

Table 5 Health promotion

\begin{tabular}{llllll}
\hline $\begin{array}{l}\text { Have you talked to anyone or been } \\
\text { given information about: (Answer) }\end{array}$ & $\begin{array}{l}\text { Matched } \\
\text { pairs }\end{array}$ & $\begin{array}{l}\text { Number of } \\
\text { subjects }\end{array}$ & $\begin{array}{l}\text { Number } \\
\text { of controls }\end{array}$ & p value & $\begin{array}{l}95 \% \text { CI of the } \\
\text { difference }\end{array}$ \\
\hline $\begin{array}{l}\text { How your body changes as you } \\
\text { grow up (Yes) }\end{array}$ & 78 & 64 & 72 & 0.096 & $-21 \%$ to $0.1 \%$ \\
$\begin{array}{l}\text { Sexuality, being straight, gay, etc } \\
\quad \text { Yes) }\end{array}$ & 76 & 42 & 53 & 0.071 & $-28 \%$ to $0.4 \%$ \\
$\begin{array}{l}\text { Sex and contraception (Yes) } \\
\text { Unprotected sex and HIV (Yes) }\end{array}$ & 71 & 43 & 57 & 0.004 & $-32 \%$ to $-7 \%$ \\
\hline
\end{tabular}

Table 6 Emotional and behavioural health: comparison between child and carer/parent scores (children aged 10-16 years)

\begin{tabular}{lll}
\hline Measure & $\begin{array}{l}\text { Mean difference between subjects' } \\
\text { and carers'scores }(95 \% \text { CI) }\end{array}$ & $\begin{array}{l}\text { Mean difference between controls' } \\
\text { and parents'scores (95\% CI) }\end{array}$ \\
\hline Interpersonal relationships & $-0.46(-7.62 \text { to }-0.51)^{\star}$ & $0.39(-1.50$ to 2.27$)$ \\
Anxieties and worries & $-0.49(-4.32$ to 3.34$)$ & $0.16(-2.28$ to 2.60$)$ \\
Behavioural problems & $8.76(3.94 \text { to } 13.58)^{\star}$ & $2.62(-0.35$ to 5.60$)$ \\
\hline${ }^{\star} \mathrm{p}<0.05$. & &
\end{tabular}

advice about contraception (table 5). Three looked after girls had been or were pregnant, and one boy admitted to having made his girlfriend pregnant.

Table 6 compares parents' and carers' views with those of the children. For the control group, parents' views of their children's emotional and behavioural health did not differ significantly from the views of the children themselves. However, carers had significantly less appreciation of the difficulties with interpersonal relationships encountered by the children in their care, and perceived greater behavioural problems $(\mathrm{p}<0.05)$.

\section{Discussion}

This study is unique: it is case controlled, evaluates the health and needs of those who have been looked after for at least six months, and documents the views of the young people themselves, using a structured questionnaire. The views of parents and carers were also sought. Our findings are based on 119 subjects. Of 364 children initially identified by Social Services, 81 were no longer in care in the area under study (see fig 1), which indicates a "response rate" of $42 \%$. Participation was declined in 135 cases, most giving no reason. Difficulty in accessing subjects is typical of studies involving children placed away from home, and reflects the extreme instability of the care system. ${ }^{20}$ It is possible that we missed children in less stable placements, a factor which can increase the risk of health problems, ${ }^{21}$ but an analysis of the demographic details of a $16 \%$ sample of "refusers" did not support this, and overall the distribution by age and sex in our sample reflects those in the care system. We believe that the loss of subjects was in part a result of the very prescriptive consent conditions which we were required to follow.

This study confirms evidence from observational studies that looked after children have considerable unmet health and health care needs, particularly in respect of their emotional and mental health, and also in health promotion. Immunisation status (as judged by child or carer recall) is worse than for children in their own homes, but we have not found significant chronic physical ill health among children in local authority care, and skin disorders were more commonly reported by children living in their own homes. Children in care appear to be attending for their statutory medical examinations (as judged by the frequency with which they are having hearing and eyesight tests) and we have found a more optimistic picture of physical health than has been found in previous uncontrolled, observational studies from the $\mathrm{UK}^{8}{ }^{9}$ and USA. ${ }^{3-6}$ The majority of reported studies looked at the health status of children entering care, and it is notable that Bamford found an improvement in the physical health of children during the care experience. $^{7}$

Our results are in tune with those reported in a two stage study of 263 children in out-ofhome placement in six provinces in Canada which used the Looking After Children Assessment and Action Records as a research instrument, and compared the results with data from the National Longitudinal Survey of Children and Youth. ${ }^{22}$ The authors comment that "the Looking After Children sample appeared to enjoy better (physical) health than the literature would lead us to believe" (p. 120).

We hope that the good picture of physical health that we have shown for children who have been in care for at least six months reflects the concerted efforts that have been made in the last few years by community paediatricians in Wales, in collaboration with local authorities, to improve attendance and quality of medical examinations. ${ }^{10}$ All children received into local authority accommodation are offered a "health assessment" by community paediatricians, and social services are automatically informed if they fail to attend. Assessment follows the guidelines from the British Agencies for Adoption and Fostering ${ }^{23}$ with a clear statement as to who is responsible for any recommended action. The child's immunisation status is available at the appointment and arrangements are made to rectify any deficiencies. Growth is monitored and any clinically indicated referrals are made. Locally there are no significant waiting list problems for children's services, with the important exception of child and adolescent mental health services. Some health promotion advice is given but neither the venue nor the mode of delivery is appropriate for this.

While emotional health and behavioural problems may be identified at the medical assessment, it is clear that they are not adequately addressed. The Royal College of 
Psychiatrists acknowledges that social services departments have had great difficulty in many parts of the country in accessing mental health services for looked after children. ${ }^{24}$ Given the high level of mobility within the care system it is likely that many children waiting for appointments with mental health professionals will have moved before they can be seen. In the absence of timely treatment or advice their mental health problems may contribute to the breakdown of their placements. We have shown that foster carers appear to understand the children they look after less well than parents, which may contribute to the difficulty they have coping with them. Bed wetting was much more common among looked after children and continued to a later age, creating embarrassment for the child and practical problems for carers.

School may be the first place where mental health problems manifest themselves. The school health service could play a more proactive and supportive role and social workers need to be in close touch with schools over health as well as educational issues, including health education. There is a need for Social and Education Services to work together, which has been clearly documented in relation to looked after children's lack of educational achievement $^{2526}$ and this cooperation should also include health services.

There is also a need for community health services to take a more proactive approach to ensure that important health messages reach those who are most in need of them. This includes encouraging them to desist from behaviour and activities which threaten their present and future health, presenting the information in an attractive and acceptable form. Standard health promotion and education are not sufficient for these children, who are likely to miss health education in school and often come from families with unhealthy life styles. Sexual health, substance misuse, and smoking are all areas that need specific attention.

There have been recent attempts to set a more comprehensive agenda for addressing the complex health needs of children in the care system, ${ }^{10}{ }^{14}$ and the problem was highlighted in 1997 by the Children's Safeguards Review. ${ }^{27}$ More recently, the Waterhouse enquiry into the abuse of children in care in north Wales pointed to significant emotional problems affecting children in the residential care system, although it did not make specific recommendations with regard to health. ${ }^{28}$

The serious lack of local health based services available to support these children and young people has been acknowledged by the National Assembly for Wales, who note "there is clear evidence that (looked after children) are cumulatively and disproportionately disadvantaged in many spheres when compared to other children". ${ }^{29}$ The Assembly recommends that further research is urgently needed to create a better basis for planning.

In conclusion, although the physical health of children in care in south west Wales is no worse than that of children living in their own homes, there are still serious deficiencies in their overall health and well being, particularly in emotional health and behaviour. It is essential that health service provision for looked after children is given high priority in the future planning of health and social services.

Contributors: JGW developed the protocol, obtained funding, monitored the study, drafted and edited the paper, and acts as guarantor for the paper. SJ conceived the study, developed the protocol, obtained funding, led the study team, analysed the qualitative data, and edited the paper. AM contributed to the protocol, liaised with health and social care, monitored the study, analysed qualitative health data, and edited the paper. WYC contributed to the protocol, calculated the sample size, monitored data collection, validated and analysed the data, and edited the paper. AL modified and piloted the data collection instrument, liaised with local authorities, collected data, trained interviewers, validated data collection, analysed qualitative data, and edited the paper. $\mathrm{HH}$ validated data collection, analysed the data, and edited the paper. We would like to acknowledge the sure support given by the Social Services in Swansea, Bridgend, Neath Port Talbot, and Pembrokeshire and for their help in dentifying subjects. We are grateful for the support and advice given by members of the Study Advisory Group (Mr Ray Ciborowski, Assistant Director, Child and Family Services, Neath Port Talbot Social Services Department; Dr Janet Crocket, Consultant Community Paediatrician, Bridgend and
District NHS Trust; Ms Pat Davies, Pupil and Parent Support District NHS Trust; Ms Pat Davies, Pupil and Parent Support Manager, Department of Education, City and County of Swan-
sea; Dr Ann Delahunty, Medical Adviser to FHSA, Iechyd sea; Dr Ann Delahunty, Medical Adviser to FHSA, Iechyd
Morgannwg Health; Mr Marcus Hill, Project Manager, Wales Office of Research and Development; Dr Heather Payne, Senior Lecturer, University of Wales College of Medicine; Mr Drew Reith, Director Barnardos, Wales and South West Division; Ms Jenny Robson, Development Manager, The Who Cares? Trust, London; Mr Mark Roszkowski, Assistant Director, Child and Family Services, Department of Social Services, City and County of Swansea; Dr John Talbot, Consultant Child and Adolescent Psychiatrist, Swansea NHS Trust; Mr Richard Wolfe, Assistant Director, Services for Children and Families, Bridgend). We thank Dr Lorna Price for assistand Families, Writh the analysis and validation of health data, and Mrs Gaynor Demery Office of Research \& Development.

1 Bebbington A, Miles J. The background of children who enter local authority care. British fournal of Social Work 1989;19:348-69.

2 Kilroe S. Health. In: Jackson S, Kilroe S, eds. The looking after children reader. London: HMSO, 1996.

3 Hochstadt NJ, Jaudes PK, Zimo DA, Schachter J. The medical and psychosocial needs of children entering foster care. Child Abuse Negl 1987;11:53-62.

4 Chernoff R, Combs-Orme J, Risley-Curtiss C, Heister A. Assessing the health status of children entering foster care. Paediatrics 1994;93:594-601.

5 Halfon N, Mendonca A, Berkowitz G. Health status of children in foster care. The experience of the Center for the Vulnerable Child. Arch Pediatr Adolesc Med 1995;149:38692.

6 Blatt SD, Saletsky RD, Meguid V, et al. A comprehensive multidisciplinary approach to providing health care for children in out of home care. Child Welfare 1997;76:33147.

7 Bamford F, Wolkind SN. The physical and mental health of children in care. London: Economic and Social Research Council, 1988.

8 Mather M, Humphrey J, Robson J. The statutory medical and health needs of looked after children. Time for a radical review? Adoption and Fostering 1997;21:36-40.

9 Butler I, Payne H. The health of children looked after by the local authority. Adoption and Fostering 1997;21:28-35.

10 Payne H, Butler I. Improving the health care process and determining health outcomes for children looked after by the local authority. Ambulatory Child Health 1998;4:16572 .

11 McCann JB, James A, Wilson S, Dunn G. Prevalence of psychiatric disorders in young people in the care system. BMF 1996;313:1529-30.

12 Arcelus J, Bellerby T, Vostanis P. A mental health service for young people in the care of the local authority. Clinical Psychology and Psychiatry 1999;4:233-45.

13 Butler J, Vostanis P. Characteristics of referrals to a mental health service for young people in care. Psychiatric Bulletin 1998;22:85-7.

14 The National Assembly for Wales. New draft guidance. Promoting health for looked after children. Cardiff: The National Assembly for Wales, 2000.

15 DHSS. Looking after children. Assessment and action records. London: DHSS

16 The Statistical Package for Social Sciences (SPSS for Windows), release 8.0.1. Chicago: SPSS, 1998. 
17 Campbell MJ, Machin D. Medical statistics. A common sense approach, 3rd edn. Chichester: John Wiley \& Sons, 1999

18 Bland JM, Altman DG. Statistical methods for assessing agreement between two methods of clinical measurement. Lancet 1986;307:10.

19 Townsend P, Phillimore P, Beattie A. Health and deprivation inequality and the north. London: Croom Helm, 1988.

20 Jackson S, Thomas N. On the move again: what works in creating stability for looked after children. Ilford: Barnardos, 1999.

21 Department of Health. Children looked after at 31 March 1994 to 1998, with three or more placements during the year. London: Department of Health, 1999.

22 Kufeldt K, Vachon J, Simard M. Looking after children in Canada. Final report to Social Development Partnerships of Human Resources Development Canada. University of New Brunswick, Universite Laval, 2000.

23 British Agencies for Adoption and Fostering. Medical report and functional assessment of child or young person referred for adoption/accommodated/received into care. London: BAAF, adoption/.
24 Richardson J, Joughin C. The mental health needs of looked after children. London: Royal College of Psychiatrists/ Gaskell, 2000

25 Fletcher-Campbell F. The education of children who are 'looked after'. Slough: National Foundation for Education Research, 1997.

26 Jackson S. Promoting the educational achievement of looked after children. In: Cox T, ed. Combatting educational disadvantage: meeting the needs of vulnerable children. disadvantage: meeting the

27 Utting W. People like us: the report of the review of the safeguards for children living away from home. London: Department of Health/The Welsh Office, 1997.

28 Lost in Care Report. Report of Tribunal of Inquiry into the abuse of care in the former County Council areas of Gwynedd and Clwyd since 1974. House of Commons, London (The Waterhouse Report), 2000.

29 National Assembly for Wales. All Wales Strategy for Child and Adolescent Mental Health Services. Cardiff: The National Assembly for Wales, 2000.

\section{Helicobacter pylori in minority group children}

Helicobacter pylori infection is usually acquired in childhood but the factors predisposing to infection are not well understood. A study of children from minority groups in Houston, Texas (Hoda M Malaty and colleagues. Clinical Infectious Diseases 2001;32:1387-92) has illustrated the importance of socioeconomic conditions.

The study included 273 black and 83 Hispanic children aged 2-16 years attending day care centres (the school age children attended before and after school). $H$ pylori infection was tested for using the ${ }^{13} \mathrm{C}$ urea breath test.

The overall prevalence of $H$ pylori infection was $24 \%$, increasing from $14 \%$ at age $2-5$ years to $49 \%$ at age $11-16$ years. There were no significant differences in infection rates between boys and girls and between black and Hispanic children. Risk factors for $H$ pylori infection included crowded day centres, crowding at home, and low level of maternal education. Breastfeeding was protective independently of the mother's education.

In this group of children, overcrowding and the mother's low level of education were the main environmental factors predisposing to $H$ pylori infection.

ARCHIVIST 